\title{
Sensitivity and Specificity of Full Outline of Unresponsiveness Score and Glasgow Coma Scale towards Patients' Outcomes at the Intensive Care Units
}

\author{
Ika Silvitasari ${ }^{1}$, Hery Djagat Purnomo ${ }^{2}$, Untung Sujianto ${ }^{3}$ \\ ${ }^{I}$ (Master Student of Nursing at Universitas Diponegoro-Indonesia), \\ ${ }^{2}$ (Lecturer of Nursing and Medical Study Program at Universitas Diponegoro-Indonesia) \\ ${ }_{3}^{3}$ (Lecturer of Nursing Study Program at Universitas Diponegoro-Indonesia)
}

\begin{abstract}
:
Study Objective: Glasgow Coma Scale (GCS) is an instrument which is generally used to assess the patients' level of consciousness. However, in certain patients, the GCS cannot function properly to assess the patients' verbal responses. To enhance this instrument, the Full Outline of unresponsiveness (FOUR) score was therefore developed. This study aimed to determine the sensitivity and specificity of the FOUR score and the GCS in assessing the level of consciousness towards the outcomes of the patients in the ICUs.

Design: observational study.

Method and Measurement: The population was all patients admitted to the ICUs. The samples were 74 patients and 2 nurse observers who were selected using a consecutive sampling technique. The data were statistically analyzed using the Receiver Operating Characteristics (ROC) and the $2 \times 2$ table.

Result: The results of the GCS test showed that the scores of sensitivity and specificity were 0.722 and 0.737 consecutively. Meanwhile, the FOUR showed a score of sensitivity and specificity of 0.861 and 0.816 . The Area Under Cover (AUC) scores of the GCS and the FOUR were 0.859 and 0.893 consecutively towards the outcomes of the patients in the ICUs.Value of the sensitivity and specificity of the FOUR score higher than the GCS and sensitivity FOUR score higher than specificity.

Conclusion: The scores of sensitivity and specificity of the FOUR were higher than the GCS. The FOUR instrument can be used as an replace of the GCS to assess the level of consciousness towards the patients' outcomes in the ICUs.
\end{abstract}

Keywords: FOUR score, GCS, sensitivity, specificity

\section{Introduction}

Intensive care unit is an independent part of a hospital with particular staff and equipments. ${ }^{1}$ A critically ill patient who is treated in ICU ward has high level of morbidity and mortality caused by various diseases. ${ }^{2}$ General clinical symptoms which are usually found in ICU ward are critically ill patients with tachypnea, tachycardia, hypotension, and disorder of conscious (such as lethargy, confusion, agitation or decreased level of consciousness). ${ }^{3}$ Level of consciousness is a sensitive indicator of neurological function, therefore an assessment on level of consciousness is needed. ${ }^{4}$ Glasgow Coma Scale (GCS) is an instrument which is broadly used to discover the level of brain injury and the level of coma of a patient with head injury. ${ }^{5}$ The GCS instrument has been tested for its validity and reliability which result was good and it has good correlation on the result of patients' outcome in forms of the number of mortality in Intensive Care Unit. ${ }^{6,7}$ This GCS instrument is simple, practical, standardized, has three assessment components including eyes response, verbal response, and motoric response in which each component has different score. ${ }^{8}$

The assessment using GCS has not completely facilitated the level of consciousness assessment, particularly on the patients with the decrease of consciousness who are intubated, the verbal component on GCS is difficult to assess. GCS components were unable to facilitate the assessment on patients with locked syndrome. ${ }^{9,10}$ A new instrument was made to complete the GCS instrument which still has some shortcomings, and it is called Unresponsiveness Score (FOUR score). ${ }^{11}$ FOUR score instrument has four assessment components consist of eyes response, brainstem response, motoric response and respiratory response. Each component is valued $0-4 .{ }^{11}$ This instrument does not include verbal response so that the patients who are either intubated or unintubated are able to be assessed. The result of the study showed different sensitivity and specificity scores with different cut off score as well. ${ }^{9,11,12}$. An alternative instrument to assess level of consciousness is needed in order to fill the limitations of GCS components. The instrument needed is an instrument that is able to provide detail neurological information, accessible, and its interpretation can be used to predict the patient's outcome in ICU. 


\section{Material and Method}

This study was an observational research conducted to the respondents who were hospitalized in ICU of RSUD Dr. Moewardi, Surakarta. The research was conducted from August to October 2016. The inclusion criteria were adult patients aged minimum $\geq 18$-year-old who experienced decrease of consciousness level. The patients did not receive sedative drug or neuro blocker. The exclusion criteria were the patients who had the history of hearing and visual impairment. The patients who had compos mentis consciousness were not willing to be the respondents of the study. The instrument had undergone face validity test by clinic, academic and language experts. The researcher conducted uniformity perception to the candidate of observers and both of the observers agreed not to talk and show the result of the assessment. Both examiners were tested on their assessing reliability using Kappa test. There were 74 respondents whose level of consciousness were measured qualitatively by the observers which then the assessments were continued using GCS and FOUR score by two observers in the morning shift, which then the patients' progresses were monitored for the next 7 days in order to discover the patients' prognosis. The result of assessment was analyzed using ROC and $2 \times 2$ table.

The respondents' distributions based on age, gender, medical diagnosis, medical treatment, clinical consciousness and outcome are as follows:

Table 1.Respondents characteristics

\begin{tabular}{|l|l|l|}
\hline Variable & N & \% \\
\hline Age & & \\
18-40-year-old & 21 & 28,4 \\
41-60-year-old & 41 & 55,4 \\
Z60 year-old & 12 & 16,2 \\
\hline Gender & & \\
Male & 32 & 43,2 \\
Female & 42 & 56,8 \\
\hline Medical diagnose & & \\
Neurological disorder & 36 & 48,6 \\
Pulmonary disorder & 6 & 8,1 \\
Gastrointestinal disorder & 4 & 5,4 \\
Musculoskeletal disorder & 11 & 14,9 \\
Infection & 8 & 10,8 \\
Metabolism and endocrinal disorders & 2 & 2,7 \\
Kidney disorder & 1 & 1,4 \\
Gynecology disorder & 6 & 8,1 \\
\hline Medical treatment & & \\
Intubated & 28 & 37,8 \\
Unintubated & 42 & 56,8 \\
Tracheostomy & 4 & 5,4 \\
\hline Clinical Consciousness & & \\
Apathic & 23 & 31,1 \\
Somnolent & 7 & 9,5 \\
Sopor & 19 & 25,7 \\
Coma & 25 & 33,8 \\
\hline Outcome & & \\
Alive & 36 & 48,6 \\
Death & 38 & 51,4 \\
\hline
\end{tabular}

Table. 2. Examiner reliability with GCS and FOUR score using Kappa test

\begin{tabular}{|l|l|l|}
\hline & FOUR score & GCS \\
\hline Kappa & 0.891 & 0.973 \\
\hline
\end{tabular}

Table. 3. Sensitivity and specificity of FOUR score and GCS

\begin{tabular}{|l|l|}
\hline FOUR score & Outcome 7 day \\
\hline Sensitivity & 0,861 \\
\hline Specificity & 0,816 \\
\hline Positive Predictive Value & 0,816 \\
\hline Negative predictive value & 0,861 \\
\hline Accuracy & 0,838 \\
\hline AUC & 0,893 \\
\hline GCS & Outcome 7 day \\
\hline Sensitivity & 0,722 \\
\hline Specificity & 0,737 \\
\hline Positive predictive value & 0,772 \\
\hline Negative predictive value & 0,737 \\
\hline Accuracy & 0,729 \\
\hline AUC & 0,859 \\
\hline &
\end{tabular}




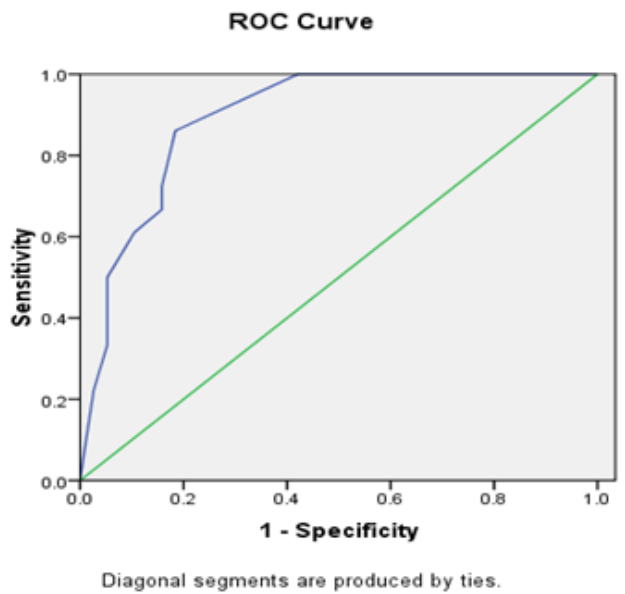

Graphic 2. ROC FOUR score

Table 4. Crosstabulation FOUR score

\begin{tabular}{|ccccc|}
\hline & & \multicolumn{2}{c}{ Outcome } & Total \\
\cline { 2 - 4 } & & Alive & Died & \\
\hline FOUR & $>6$ & 31 & 7 & 43 \\
score & $\leq 6$ & 5 & 31 & 31 \\
Total & & 36 & 38 & 74 \\
\hline
\end{tabular}

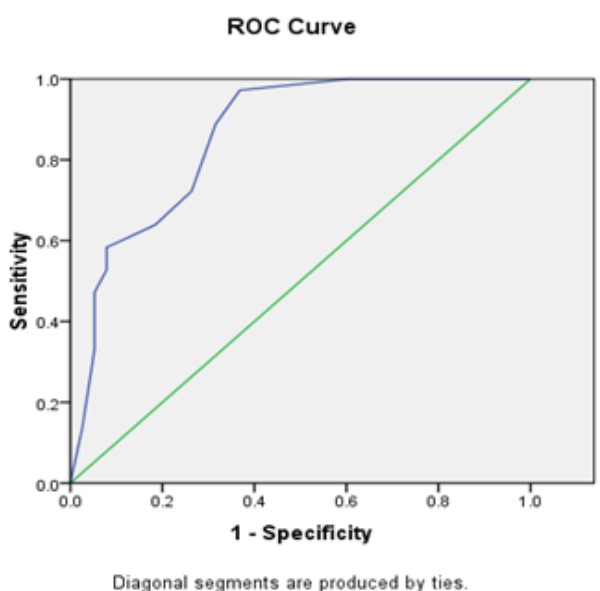

Graphic 1. ROC GCS

Table 5. Crosstabulation GCS

\begin{tabular}{|lcccc}
\hline & & \multicolumn{2}{c}{ Outcome } & Total \\
\cline { 2 - 4 } & & Alive & Died & \\
\hline GCS & $>5$ & 28 & 8 & 36 \\
& $\leq 5$ & 8 & 30 & 38 \\
Total & & 36 & 38 & 74 \\
\hline
\end{tabular}

\section{Discussion}

The result of the study showed that the sensitivity and specificity of FOUR score with the patients' outcome in ICU and cut off value of 6 were $0.861 ; 0.816$ respectively. While the sensitivity and specificity of GCS with cut off value of 5 were $0.722 ; 0.737$ respectively. The result showed that of the sensitivity and specifisity of the FOUR score higher than the GCS.The result of the study was supported with a research conducted by Baratloo on patients with head injuries when they entered the hospital gained sensitivity and specificity values for GCS instrument were 0.842; 0.886 respectively, while the values gained for FOUR score were $0.869 ; 0.884$ respectively. ${ }^{13}$ In general, the higher cut off resulted in better outcome. The AUC score of GCS and FOUR score showed very good results of 0.859 and 0.893 respectively. A good AUC score showed that the mortality probability to occur in the lowest total score of FOUR score and GCS was very high. The high AUC score of this study was also supported by other studies which showed AUC score for GCS was 0.815 , while the AUC for FOUR score was $0.834 .{ }^{14}$ Another study gained a very high score for AUC GCS on patients' mortality on their initial entrance to the hospital of 0.9116 while FOUR score was $0.9272 .{ }^{13}$

GCS instrument has been used for a long time. However, there are some shortcomings of this instrument such as its inability to assess verbal response of intubated patients and its inability to assess vegetative condition of a patient experiences locked syndrome. GCS instrument does not have clinical indicators to assess the brainstem death and the changes of respiratory patterns which are used to discover the development of severity coma ${ }^{10,11,15}$ However, there were numerous studies which have been conducted to assess the level of consciousness which have established good result for both validity and reliability scores of patients' mortality outcome in intensive care unit. Generally, this instrument is considered as simple and accessible to assess the level of consciousness. ${ }^{6,7}$ FOUR instrument was made to ease and accelerate the assessment of patients' level of consciousness in which GCS does not contain neurological components needed. The scores in GCS components have different total score in each response; eye scores $1-4$, motoric score $1-6$, and verbal score 1 -5 , while FOUR score has similar score on each score of $0-4$. Hence, the assessment for FOUR score is easy to remember. ${ }^{11}$ Level of consciousness is a measurement of a person's attitude and response toward him/herself and the environment. ${ }^{16}$ Arousal component and awaken situation are determined by the function of cerebral hemisphere and reticular activating system (RAS) interaction in the brainstem. Therefore, when there is a dysfunction in this channel then the patient's consciousness will be disturbed. ARAS information channel will activate hypothalamus and limbic system in cortical in arranging the emotion and attitude response such as the response of sick and loud sound. ${ }^{17}$

FOUR instrument has similar score on each component in which the maximal score is 4 and the minimal is 0 , so it eases the observer to memorize. The verbal response is not included in this instrument so that it can be used to assess the level of consciousness on patients either incubated or not. ${ }^{11}$ The assessment on level of consciousness with precise result will help the family and health workers to give medication, monitor the 
condition and development of the patients' health, give comfort and administration easiness as well as reduce the treatment cost. ${ }^{15}$ The researcher confirmed that GCS can be used to assess the level of consciousness instead of its shortcomings, while FOUR score can be used to assess the level of consciousness which was proven with the high level of sensitivity and specificity scores. The researcher still needs to gain a larger sample in order to prove that this instrument will able to be used for all patients in general and accessible for all health workers.

\section{Conclusion}

The result of the study showed that value of the sensitivity and specificity of the FOUR score higher than the GCS. Therefore, FOUR score instrument can be used as an alternative instrument to replace GCS in assessing the level of patients' consciousness in ICU with patients' outcome at 7 day in ICU.

[1]. Keputusan Menteri Kesehatan Republik Indonesia Nomor 1778/MENKES/SK/XII/2010. Pedoman Penyelenggaraan Pelayanan Intensive Care Unit (ICU) Di Rumah Sakit.

[2]. Zimmerman JE, Kramer A a, Knaus W a. Changes in hospital mortality for United States intensive care unit admissions from 1988 to 2012. Crit Care. 2013;17(2):R81

[3]. Jevon P, Ewens B, Singh J. Monitoring the Critically Ill Patient. 3rd ed. Wiley-Blackwell; 2012.

[4]. Smeltzer, Suzanne C, Bare, Brenda G. Brunner \& Suddarth's textbook of medical-surgical nursing. Edisi 12. Wolters Kluwer Health / Lippincott Williams \& Wilkins.; 2010.

[5]. Bordini AL, Luiz TF, Fernandes M, Arruda WO, Teive HAG. Coma scales A historical review. 2010;68(May):930-7.

[6]. Matheesiriwat N, Kuptniratsaikul S. The FOUR Score and Glasgow Coma Scale to Evaluate the Patients with Intubation at Emergency Room. R Thai Army Med J. 2012;65:145-52.

[7]. Wolf CCA, Nc U, Nash SK. A Head Injury Teaching Module for Prehospital Assessment. 2011;176(February):204-9.

[8]. Irawan H, Setiawan F, Dewanto G. Perbandingan Glasgow Coma Scale dan Revised Trauma Score dalam Memprediksi Disabilitas Pasien Trauma Kepala di Rumah Sakit Atma Jaya. M. 2009;Vol 60. No:437-42.

[9]. Kavipat PA. Endorsement of the FOUR Score for Consciousness Assessment in Neurosurgical Patients. Neural Med Chir. 2009;4:565-71.

[10]. Jalali R, Rezaei M. A Comparison of the Glasgow Coma Scale Score with Full Outline of Unresponsiveness Scale to Predict Patients ’ Traumatic Brain Injury Outcomes in Intensive Care Units. Crit Care Res Pract. 2014;2014.

[11]. Wijdicks EFM, Bamlet WR, Maramattom B V, Manno EM, McClelland RL. Validation of a new coma scale: The FOUR score. Ann Neurol.2005;58(4):585-93.

[12]. Akavipat Phuping, Sookplung Pimwan, KaewsinghaPranee, and MaunsaiyatPatcharin. Prediction of Discharge Outcome with the Full Outline of Unresponsiveness (FOUR) Score in Neurosurgical Patients. Acta Med. Okayama, 2011. Vol. 65, No. 3, pp. 205-210.

[13]. Baratloo A, Y MS, Safari S, Kamal A, Mbchb A, Frca D, et al. Predictive Value of Glasgow Coma Score and Full Outline of. 2016;19(3):215-21

[14]. Peng J, Deng Y, Chen F, Zhang X, Wang X, Zhou Y, et al. Validation of the Chinese version of the FOUR score in the assessment of neurosurgical patients with different level of consciousness. BMC Neurol. 2015;1-8.

[15]. Matheesiriwat N, Kuptniratsaikul S. The FOUR Score and Glasgow Coma Scale to Evaluate the Patients with Intubation at Emergency Room. R Thai Army Med J. 2012;65:145-52.

[16]. Satyanegara. Ilmu Bedah Syaraf. Jakarta: PT Gramedia Pustaka Utama; 2010.

[17]. Porth C. Essentials of pathophysiology : concepts of altered health states. Edisi 3. Wolters Kluwer Health | Lippincott Williams \& Wilkins; 2011. 